\title{
Microcornea-glaucoma-absent frontal sinuses syndrome
}

INSERM

\section{Source}

INSERM. (1999). Orphanet: an online rare disease and orphan drug data base.

Microcornea-glaucoma-absent frontal sinuses syndrome. ORPHA:2536

Microcornea-glaucoma-absent frontal sinuses syndrome is characterised by

microcornea, glaucoma and absent frontal sinuses. Less 10 cases have been described so far. The mode of transmission appears to be autosomal dominant. 